\title{
Method for Most Appropriate Plucking Date Determination based on the Elapsed Days after Sprouting with NIR Reflection from Sentinel-2 Data
}

\author{
Kohei Arai $^{1}$ \\ Faculty of Science and Engineering \\ Saga University, Saga City \\ Japan
}

\author{
Yoshiko Hokazono ${ }^{2}$ \\ Oita Prefectural Agriculture, Forestry and Fisheries \\ Research Center, Bungo-Ohno City \\ Oita, Japan
}

\begin{abstract}
Method for most appropriate plucking date determination based on the elapsed days after sprouting with Near Infrared: NIR reflection from Sentinel-2 data is proposed. Depending on the elapsed days after sprouting, tealeaf quality is decreasing. On the other hand, tealeaf yield is increasing with increasing of the days after sprouting. Therefore, there is most appropriate plucking date is very important. Usually, it is determined by the normalized Difference Vegetation Index: NDVI derived from handheld NDVI cameras, drone mounted NDVI cameras, and visible to NIR radiometer onboard satellites because NIR reflection and NDVI depend on tealeaf quality and yield. It, however, does not work well in terms of poor regression performance and species dependency. Moreover, it takes time consumable works for finding appropriate tealeaves from the acquired camera images. The proposed method uses only the days after sprouting. Next thing it has to do is to determination of sprouting date. In order to determine the date, optical sensor onboard Sentinel-2 data is used. Through experiment with the truth data taken at the intensive study area of the Oita Prefectural Agriculture, Forestry and Fisheries Research Guidance Center: OPAFFRGC, it is found that the proposed method is validated.
\end{abstract}

Keywords-Plucking date; elapsed days after sprouting; NIR reflection; sentinel-s; normalized difference vegetation index: NDVI

\section{INTRODUCTION}

Vegetation monitoring is attempted with red and photographic cameras [1]. Growth rate monitoring is also attempted with spectral observation [2].

Total nitrogen content corresponds to amid acid which is highly correlated to Theanine: 2-Amino-4-(ethyl carbamoyl) butyric acid for tealeaves so that total nitrogen is highly correlated to tea taste. Meanwhile fiber content in tealeaves has a negative correlation to tea taste. Near Infrared: NIR camera data shows a good correlation to total nitrogen and fiber contents in tealeaves so that tealeaves quality can be monitored with network NIR cameras.

It is also possible to estimate total nitrogen and fiber contents in leaves with remote sensing satellite data, in particular, Visible and Near Infrared: VNIR radiometer data. Moreover, Vegetation Cover: VC, Normalized Difference Vegetation Index: NDVI, Bi-Directional Reflectance
Distribution Function: BRDF of tealeaves have a good correlation to growth index of tealeaves so that it is possible to monitor expected harvest amount and quality of tealeaves with network cameras together with remote sensing satellite data. BRDF monitoring is well known as a method for vegetation growth [3], [4]. On the other hand, degree of polarization of vegetation is attempted to use for vegetation monitoring [5], in particular, Leaf Area Index: LAI together with new tealeaves growth monitoring with BRDF measurements [6].

It is obvious that nitrogen rich tealeaves taste good while fiber rich tealeaves taste bad. Theanine: 2-Amino-4-(ethyl carbamoyl) butyric acid that is highly correlated to nitrogen contents in new tealeaves are changed to catechin [7],[8],[9] due to sun light. In accordance with sunlight, new tealeaves growth up so that there is a most appropriate time for harvest in order to maximize amount and taste of new tealeaves simultaneously.

Depending on the elapsed days after sprouting, tealeaf quality is decreasing. On the other hand, tealeaf yield is increasing with increasing of the days after sprouting. Therefore, there is most appropriate plucking date is very important. Usually, it is determined by the normalized Difference Vegetation Index: NDVI derived from handheld NDVI cameras, drone mounted NDVI cameras, and visible to NIR radiometer onboard satellites because NIR reflection and NDVI depend on tealeaf quality and yield. It, however, does not work well in terms of poor regression performance and species dependency. Moreover, it takes time consumable works for finding appropriate tealeaves from the acquired camera images.

Method for estimation of grow index of tealeaves based on $\mathrm{Bi}$-Directional reflectance function: BRDF measurements with ground-based network cameras is proposed [10]. Wireless sensor network for tea estate monitoring in complementally usage with Earth observation satellite imagery data based on Geographic Information System (GIS) is also proposed [11]. Method for estimation of total nitrogen and fiber contents in tealeaves with ground-based network cameras is, on the other hand, proposed [12].

Monte Carlo ray tracing simulation for bi-directional reflectance distribution function and grow index of tealeaves estimation is conducted with the truth data [13] together with 
fractal model-based tea tree and tealeaves model for estimation of well opened tealeaf ratio which is useful to determine tealeaf harvesting timing [14].

Meanwhile, method for tealeaves quality estimation through measurements of degree of polarization, leaf area index, photosynthesis available radiance and normalized difference vegetation index for characterization of tealeaves is proposed [15]. On the other hand, optimum band and band combination for retrieving total nitrogen, water, and fiber in tealeaves through remote sensing based on regressive analysis is discussed [16].

Appropriate tealeaf harvest timing determination based on NIR images of tealeaves is attempted [17] together with appropriate harvest timing determination referring fiber content in tealeaves derived from ground based NIR camera images [18].

Method for vigor diagnosis of tea trees based on nitrogen content in tealeaves relating to NDVI is proposed [19]. In the meantime, cadastral and tea production management system with wireless sensor network, GIS, based system and IoT technology is created [20].

Bi-Directional Reflectance Distribution Function: BRDF model for new tealeaves and tealeaves monitoring with network cameras is well reported [21] together with BRDF model for new tealeaves on old tealeaves and new tealeaves monitoring through BRDF measurement with web cameras [22].

Estimation method for total nitrogen and fiber contents in tealeaves as well as grow index of tealeaves and tea estate monitoring with network cameras is proposed [23]. Meanwhile, multi-layer observation for agricultural (tea and rice) field monitoring is overviewed [24].

The proposed method uses only the days after sprouting. Next thing it has to do is to determination of sprouting date. In order to determine the date, optical sensor onboard Sentinel-2 data is used.

In the following section, the research background is described followed by the proposed method. Then, the experimental method together with experimental results are described. After that, concluding remarks and some discussions are also described.

\section{RESEARCH BACKGROUND}

Currently, new planting and construction of drink tea gardens are underway in Oita Prefecture, and harvesting has already begun in some of them. As the area for cultivating drink tea grows, it is necessary to improve appropriate management techniques to maintain quality and produce high yields. In this task, we will examine the technique for determining the timely work for growing and picking drink tea.

Setting the first working day is essential for making a picking plan for a large-scale drink corporation. Therefore, it is determined by measuring the Neutral Detergent Fiber: NDF value (frame picking) and predicting the yield (visually), which is performed after the number of days after sprouting of the field to be picked earliest and after the tea leaves have grown to some extent. The dissemination of technology that allows field managers to easily and accurately predict is an issue.

Growth diagnosis (remote sensing) is performed from image data, and a judgment technique for predicting the plucking time is examined (growth diagnosis based on the correlation between the near-infrared reflectance of tea leaves and the NDF value). However, as will be described later, the tendency differs depending on the variety and changes depending on the weather conditions and the like, so that a very favorable result was not obtained. Therefore, here, we decided to examine a judgment technique for predicting the plucking time based on the correlation between the number of days after sprouting, the NDF value, and total nitrogen.

\section{A. Conventional Method with NDVI}

Growth diagnosis (remote sensing) was performed from the image data, and a judgment technique for predicting the plucking time was examined (growth diagnosis based on the correlation between the near-infrared reflectance of tealeaves and the NDF value). The total nitrogen and fiber content of tealeaves are estimated from smartphone camera images acquired by tea farmers, and the optimum growth and plucking time is predicted.

Fig. 1(a) shows the photo of acquiring visible and NIR camera data at the Oita Prefectural Agriculture, Forestry and Fisheries Research Guidance Center: OPAFFRGC. On the other hand, Fig. 1(b) shows an example of the acquired photo of tea trees with visible camera from the top view while Fig. 1(c) shows an example of the acquired photo of tea trees with NIR camera from the top view. In the middle of Fig. 1(c), there is standard plaque which allows conversion from brightness of the images to reflectance. Therefore, it is possible to calculate NIR reflectance of the tealeaves in concern by comparing between brightness of the standard plaque and tealeaves.

From these images and the NDF and Total Nitrogen: TN content in the harvested tealeaves, regression analysis can be done.

\section{B. Species Depedency between NDF and TN and NIR Reflectance}

Fig. 2 shows the species dependency between NDF\&TN and NIR reflectance. Tealeaf species presented here are Okumidori, Fushun, Sayama-Kaori, Meiryoku, and Yabukita. All varieties showed a positive correlation with NDF and a negative correlation with total nitrogen. The relations between NDF\&TN and NIR reflectance, however, are different among the tealeaf species.

Table I shows the results from the linear regressive analysis between NDF\&TN and NIR reflectance. The determination coefficients $\left(\mathrm{r}^{2}\right)$ are difference each other of the tealeaf species. 


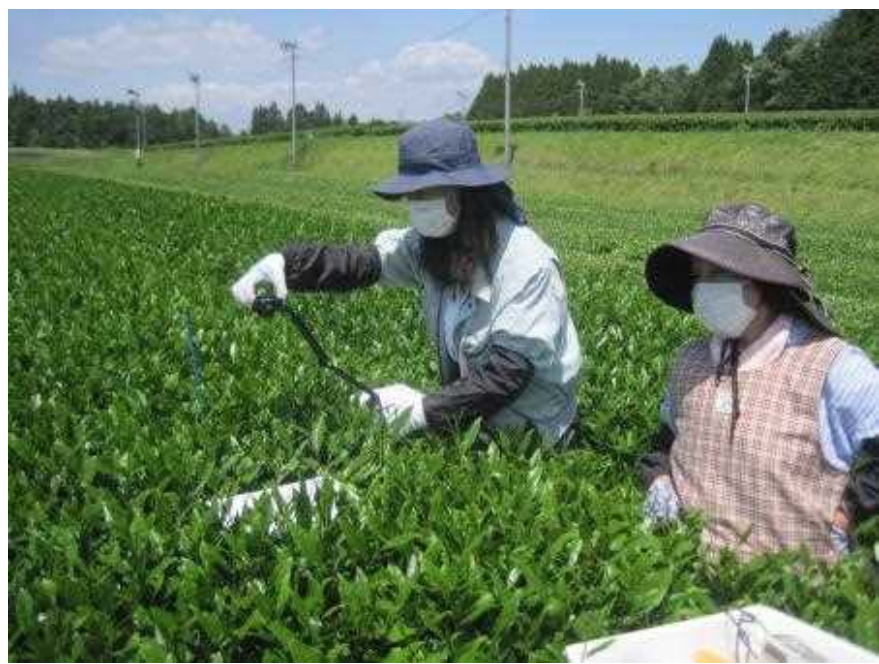

(a) Scenery of Acquisition of Photos of tee Trees

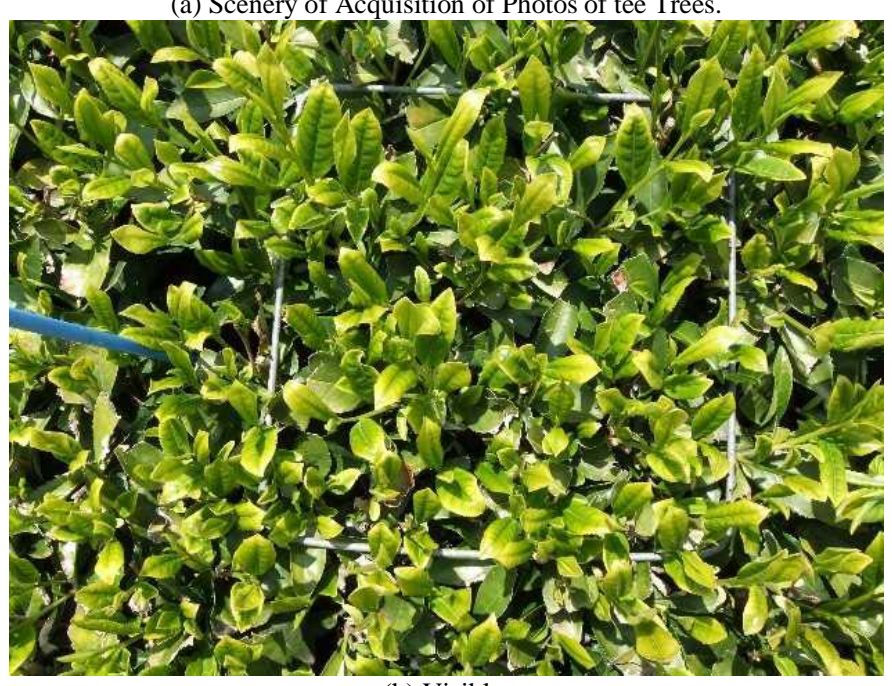

(b) Visible.

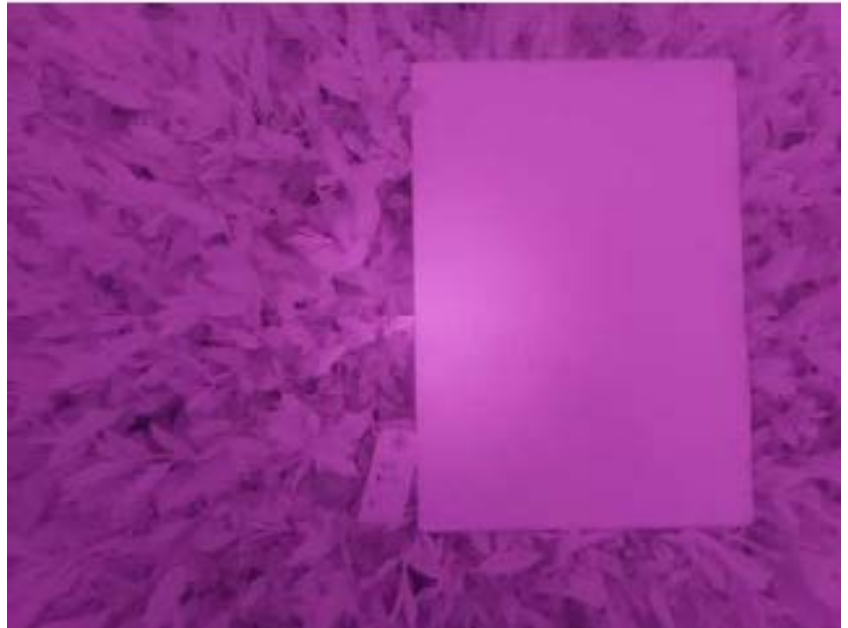

(c) NIR.

Fig. 1. Scenery of Acquiring Visible and NIR Camera Images and some Examples of the Acquired Photo of Tea Trees with Visible and NIR Cameras from the Top View.
(\%)

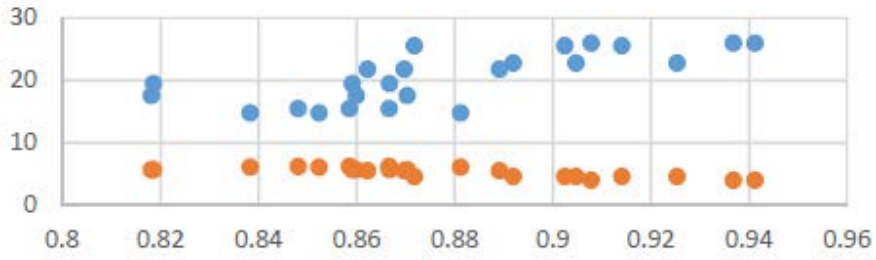

- NDF - TN

(\%)

(a) Okumidori.

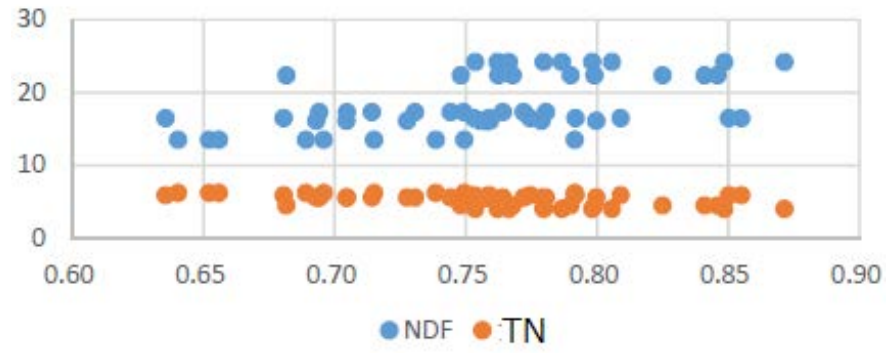

(\%)

(b) Fushun.

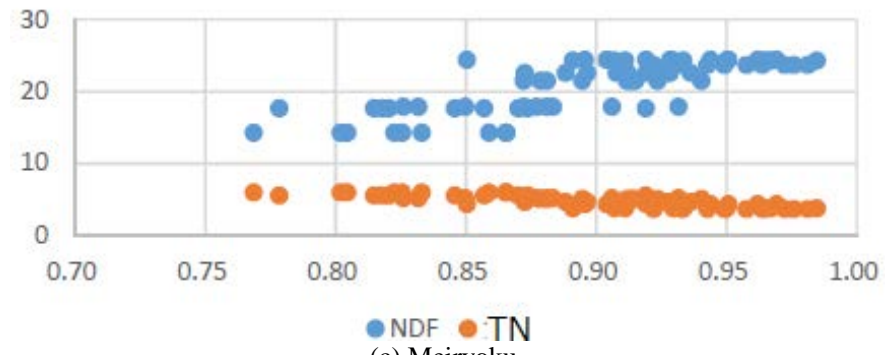

(\%)

(c) Meiryoku.

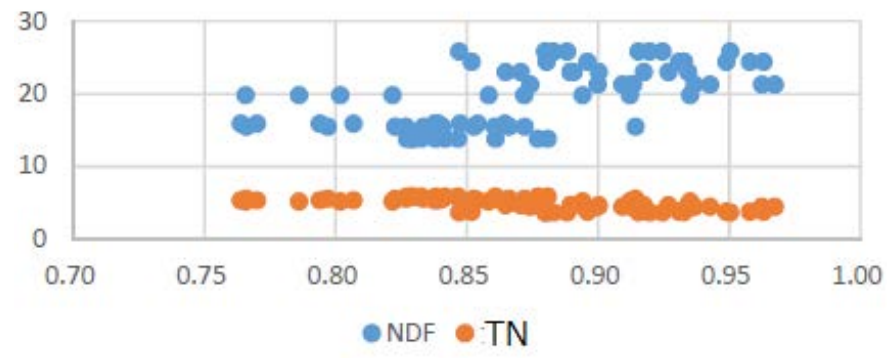

(\%)

(d) Sayama-Kaori.

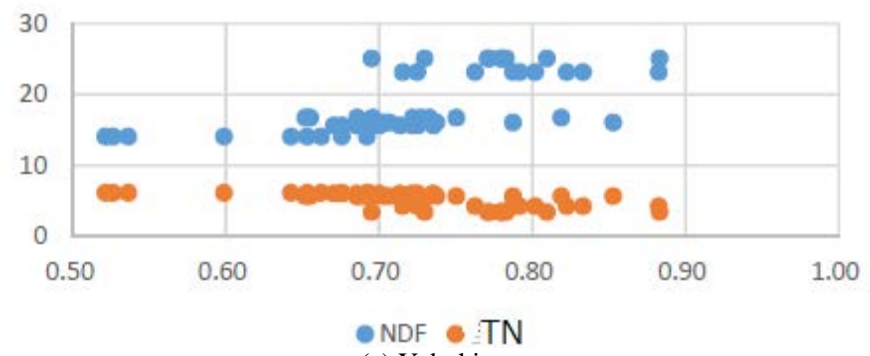

(e) Yabukita.

Fig. 2. Species Dependency between NDF\&TN and NIR Reflectance. 
TABLE I. RESULTS FROM THE LINEAR REGRESSIVE ANALYSIS BETWEEN NDF AND TN AND NIR REFLECTANCE

\begin{tabular}{|l|l|l|l|l|}
\hline \multirow{2}{*}{} & \multicolumn{2}{l|}{$\mathrm{NDF}(\%)$} & \multicolumn{2}{l|}{$\mathrm{TN}(\%)$} \\
\cline { 2 - 5 } & Linear Approx. & $\mathrm{r}^{2}$ & Linear Approx. & $\mathrm{r}^{2}$ \\
\hline Okumidori & $\mathrm{y}=89.97 \mathrm{x}-58.47$ & 0.52 & $\mathrm{y}=-18.6 \mathrm{x}+21.62$ & 0.66 \\
\hline Sayama-Kaori & $\mathrm{y}=50.36 \mathrm{x}-24.26$ & 0.37 & $\mathrm{y}=-9.27 \mathrm{x}+12.98$ & 0.38 \\
\hline Fushun & $\mathrm{y}=34.03 \mathrm{x}-7.41$ & 0.25 & $\mathrm{y}=-6.75 \mathrm{x}+10.41$ & 0.23 \\
\hline Meiryoku & $\mathrm{y}=53.34 \mathrm{x}-27.04$ & 0.61 & $\mathrm{y}=-11.89 \mathrm{x}+15.47$ & 0.63 \\
\hline Yabukita & $\mathrm{y}=34.89 \mathrm{x}-6.63$ & 0.42 & $\mathrm{y}=-8.09 \mathrm{x}+11.08$ & 0.39 \\
\hline
\end{tabular}

As a result of correlation analysis and simple regression analysis for each variety of tea leaves with near-infrared reflectance, NDF, and total nitrogen, the near-infrared reflectance increased with the lapse of growing days, and there was a positive correlation with NDF and total nitrogen. There was a negative correlation. In addition, the contribution rate $\left(\mathrm{r}^{2}\right)$ of near-infrared reflectance varied among varieties for both NDF and total nitrogen, and none showed a strong correlation exceeding 0.7. There was a weak correlation between nearinfrared reflectance, NDF, and total nitrogen content, and the results differed depending on the variety.

\section{PROPOSED METHOD}

The proposed method is based on the days after sprouting. Namely, the most appropriate harvest time can be determined with the days after sprouting. In order to determine the sprouting date, optical sensor onboard Sentinel-2 data is used. Sentinel-2 acquires $10 \mathrm{~m}$ resolution of visible to NIR sensor data every 10 days. Therefore, trend of the NIR reflectance can be derived from the sensor data.

Usually, NIR reflectance is increased after the spring pruning (Late March). Then plucking is made in Early May. Within that period, Sentinel-2 derived NIR reflectance can be gathered 5-6 times. Therefore, using these at least three time of acquired NIR reflectance, it is possible to determine the sprouting date which results in determination of the most appropriate plucking and harvest date.

\section{EXPERIMENT}

\section{A. Intensive Study Area}

The intensive study area is situated at Bungo Ohno in Oita Prefecture, Japan. Fig. 3 shows the location of our intensive study area. There is experimental tea farming area in which several species of tea trees (Okumidori, Fushun, Sayama-Kaori, Meiryoku, and Yabukita) are planted.

\section{B. Estimation of Sprouting Date}

Sprouting date can be determined by time series of Sentinel-2 of NIR reflectance, as aforementioned. All the Sentinel-2 of false colored imagery data during from Autumn pruning to just before the plucking are gathered. Fig. 4 shows such imagery data which are covered with no cloud.

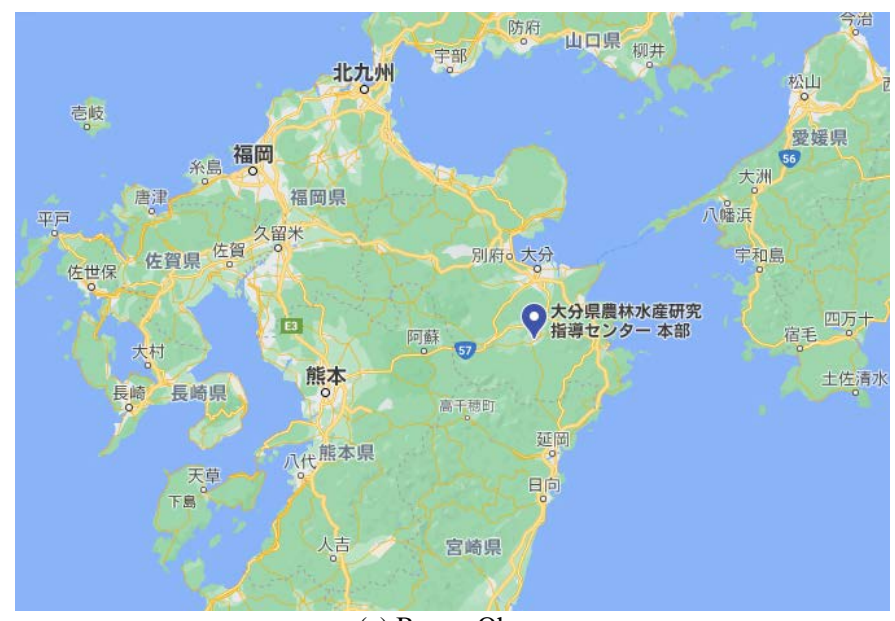

(a) Bungo Ohno.

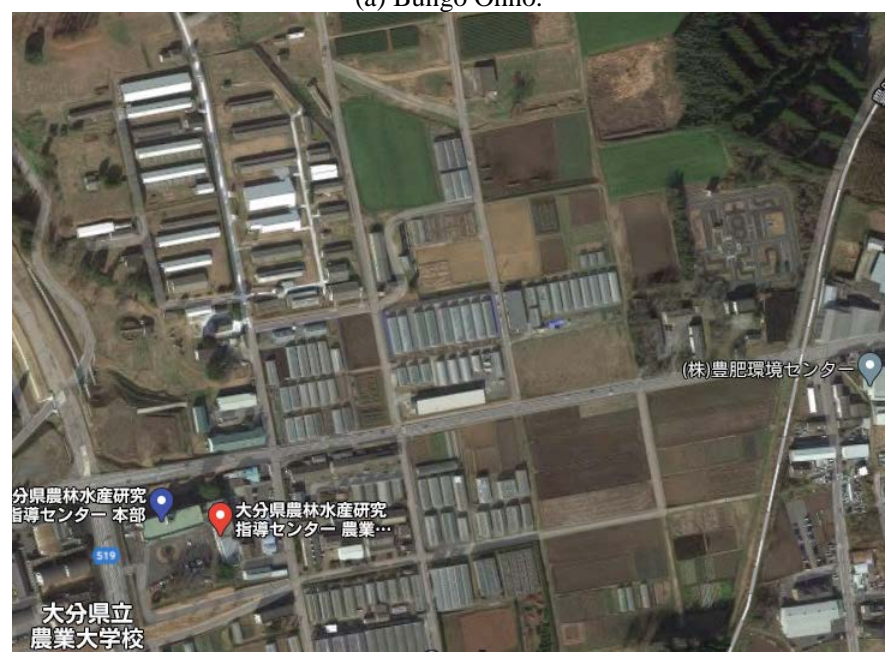

(b) Google Map.

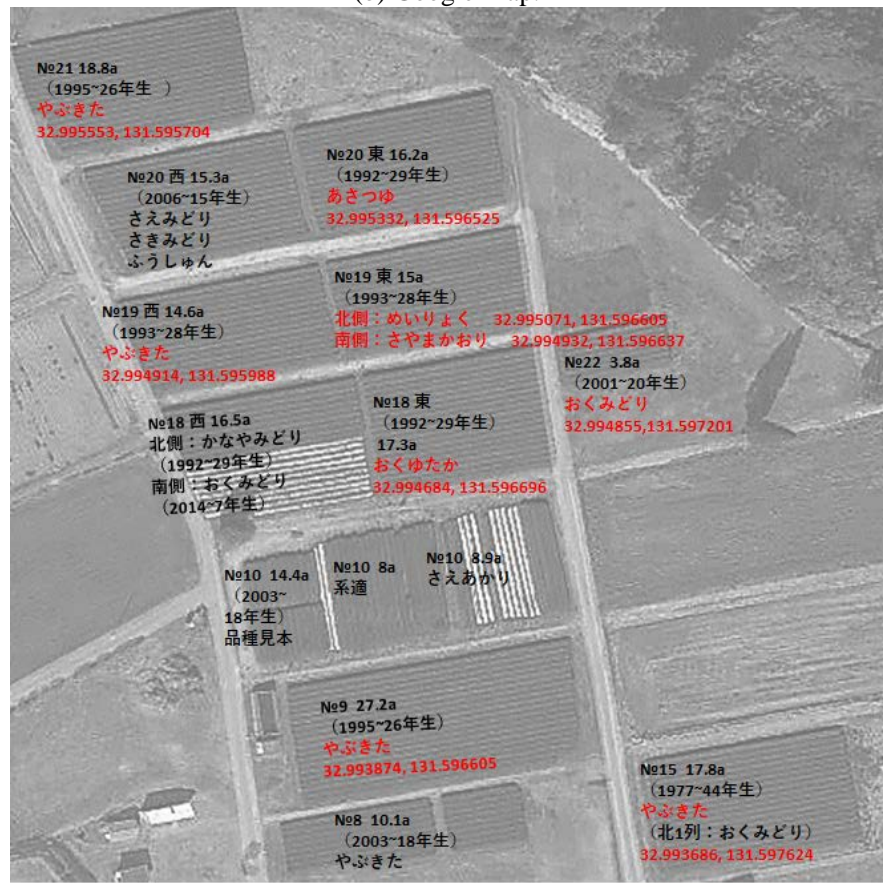

(c) Location of Tea Tree Farming Areas of Five Species.

Fig. 3. Intensive Study Area of Bungo Ohno, Oita, Japan. 

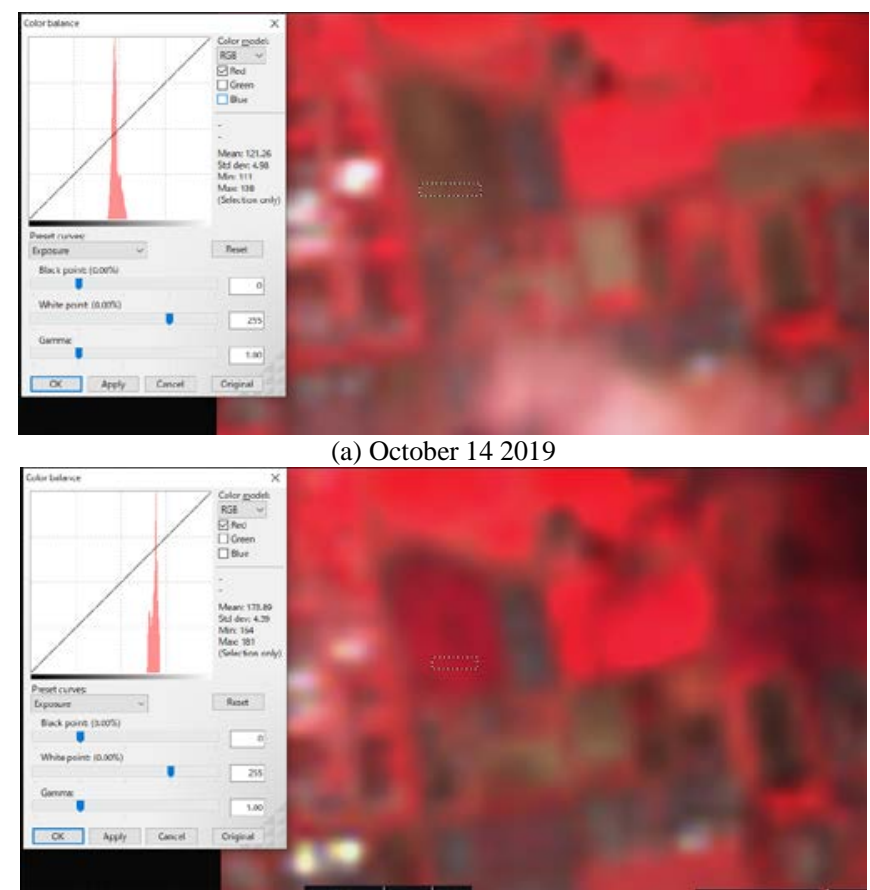

(b) November 82019

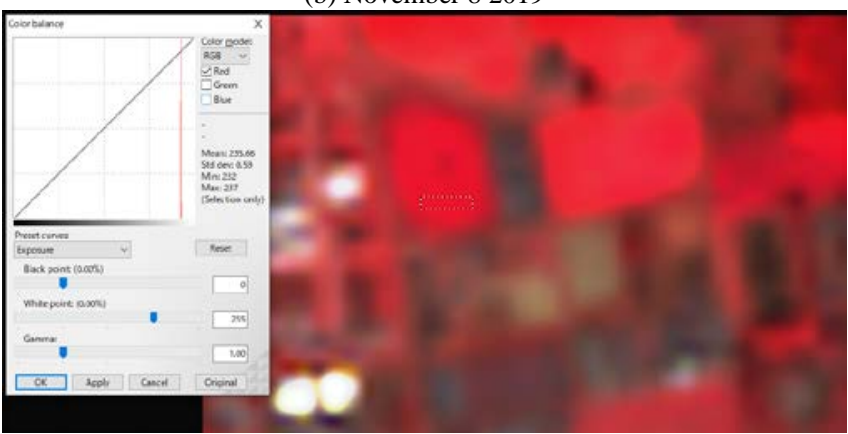

(c) November 132019
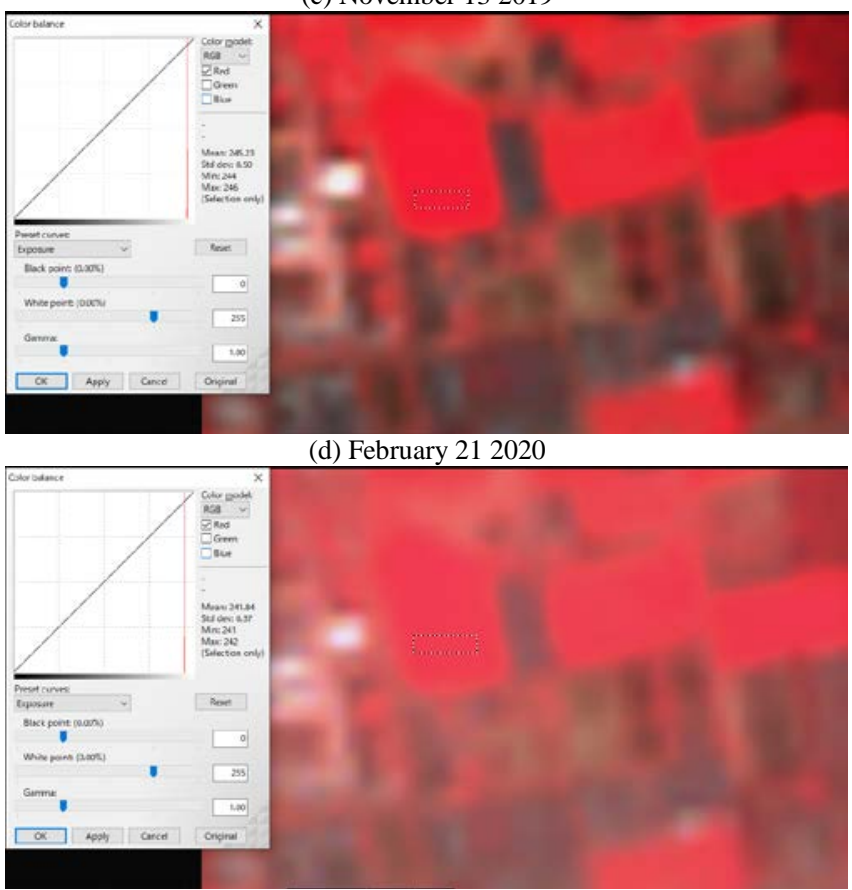

(e) March 122020

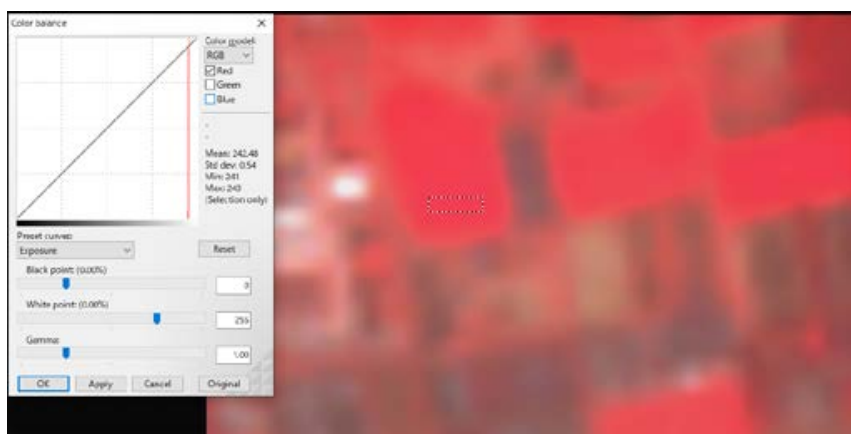

(f) March 172020

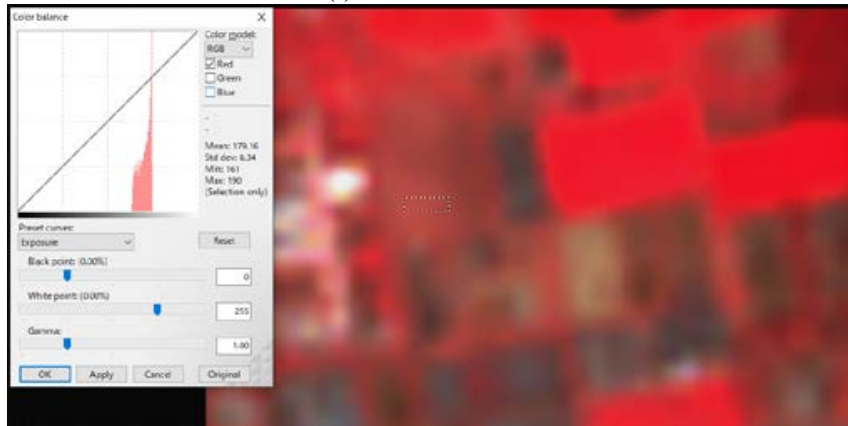

(g) April 62020

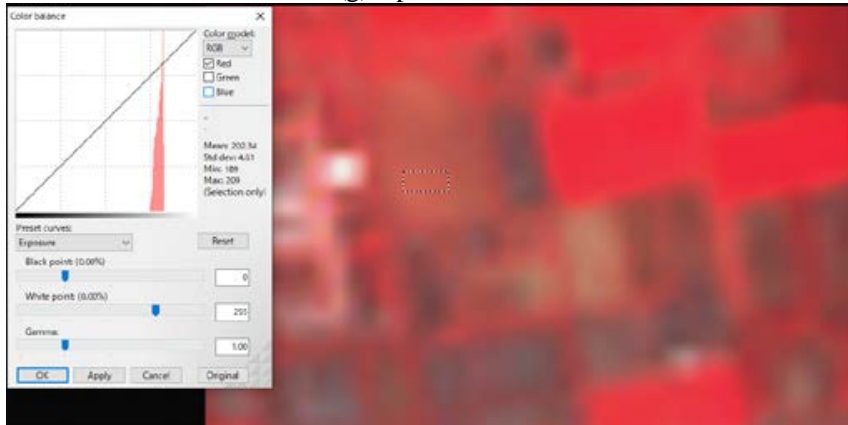

(h) April 112020

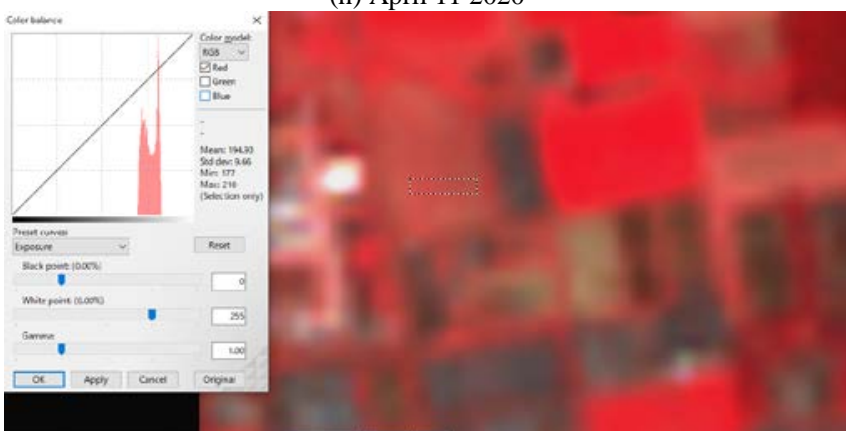

(i)April 162020

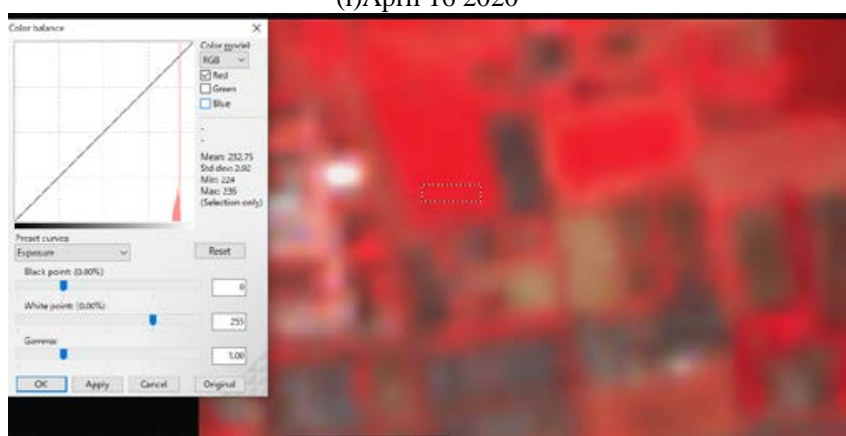

(j) May 12020 


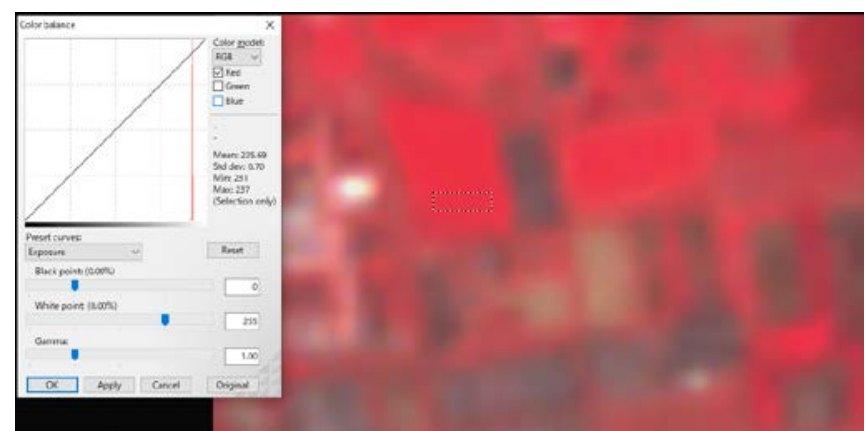

(k) May 62020

Fig. 4. Sentinel-2 of False Colored Imagery Data during from Autumn Pruning to Just before the Plucking.

In the images, histograms of NIR DN (Digital Number) representing reflectance at the intensive study area are shown. Fig. 5 shows the time series of the NIR DN. Autumn pruning is done on the $14^{\text {th }}$ October 2019. Therefore, tips of tea trees are cut which results in decreasing of NIR DN. After that, tealeaves are growing rapidly. Then NIR DN is saturated during the winter season. During from late March to the bigging of April, spring pruning is done for strength of tealeaves' vitality. Then tealeaves are grown rapidly with new flesh tealeaves. This new flesh tealeaves (Ichiban-Cha) taste good and is contained with Amino acid of Theanine and are to be tealeaves for sale.

From this time series of NIR DN data derived from Sentinel-2 NIR data which are acquired during from Spring pruning to just before the plucking (Fig. 6), sprouting date can be determined. Linear approximation is done with the time series of NIR DN data (four points of data) of Yabukita tea farming field as an example. Then sprouting date is determined as the end of March in this case. The actual sprouting dates for each tea tree species are as follows, Okumidori: $7^{\text {th }}$ April, Fushun: $28^{\text {th }}$ March, Sayama-Kaori: $3^{\text {rd }}$ April, Meiryoku: $27^{\text {th }}$ March, and Yabukita: $30^{\text {th }}$ March. Therefore, the proposed method is validated.

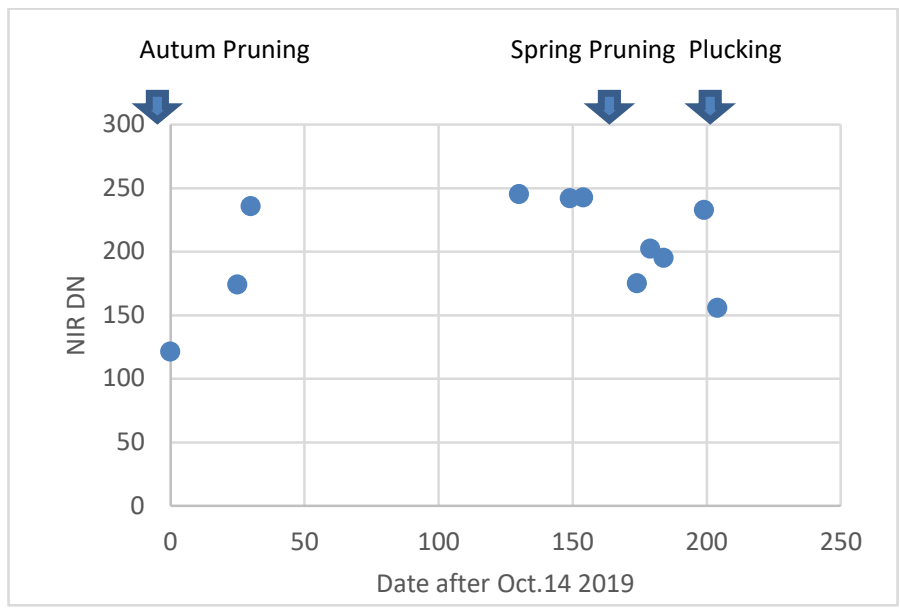

Fig. 5. Time Series of NIR DN Data Derived from Sentinel-2 of NIR Data.

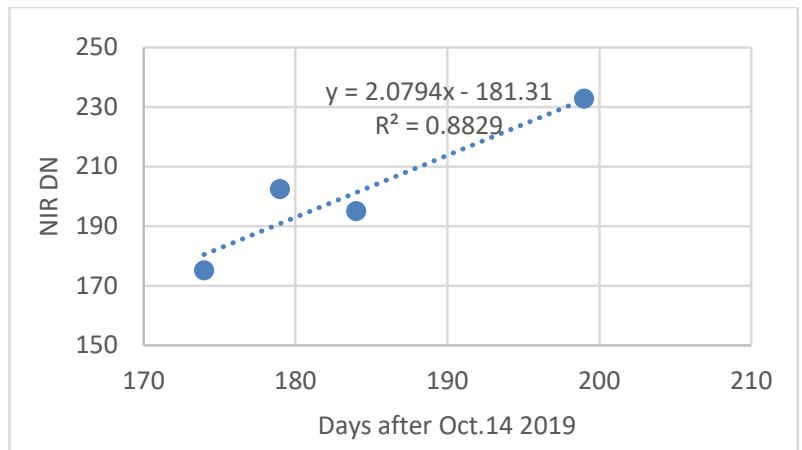

Fig. 6. Time Series of NIR DN Data Derived from Sentinel-2 NIR Data which are acquired during from Spring Pruning to just before the Plucking.

\section{Linear Regressive Analysis between TN and NDF and the Days after Sprouting}

Linear regressive analysis between TN and NDF and the days after sprouting is done for all the species. Fig. 7 shows scatter plots and linear approximation of the relation between both.

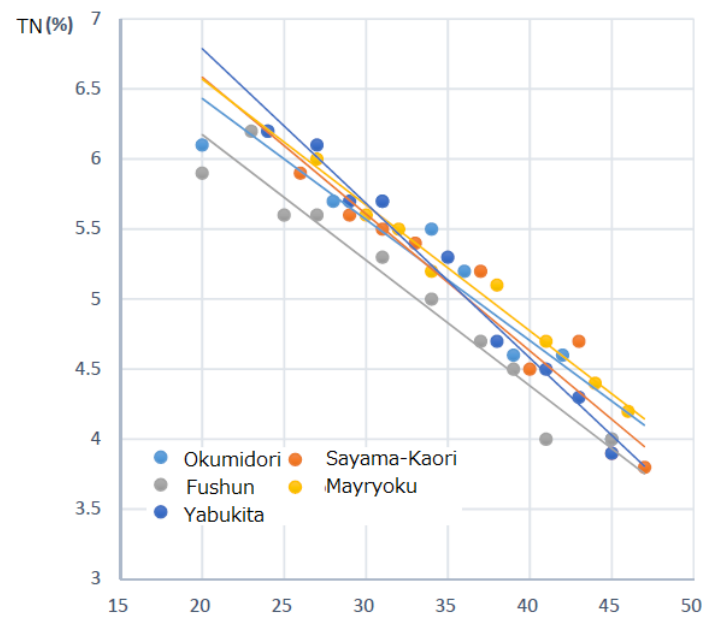

(a) TN.

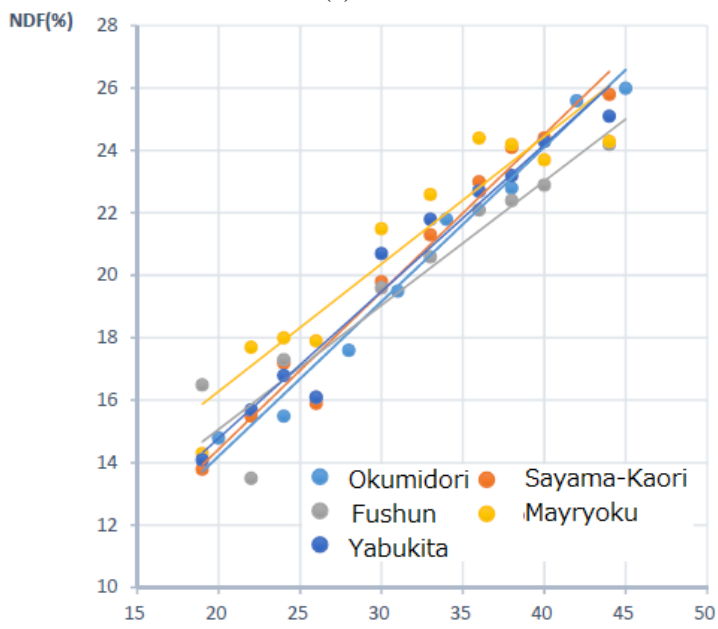

(b) NDF.

Fig. 7. Result from the Linear Regressive Analysis between TN and NDF and the Days after Sprouting is done for all the Species. 
Table II shows the results from the linear regressive analysis between NDF and TN and the days after sprouting. The determination coefficients $\left(\mathrm{r}^{2}\right)$ are difference each other of the tealeaf species.

TABLE II. RESULTS FROM THE LINEAR REGRESSIVE ANALYSIS BETWEEN NDF AND TN AND THE DAYS AFTER SPROUTING

\begin{tabular}{|l|l|l|l|l|}
\hline \multirow{2}{*}{} & \multicolumn{2}{|l|}{ NDF (\%) } & \multicolumn{2}{l|}{ TN (\%) } \\
\cline { 2 - 5 } & Linear Approx. Eq. & $\mathrm{r} 2$ & Linear Approx. Eq. & $\mathrm{r} 2$ \\
\hline Okumidori & $\mathrm{y}=0.4949 \mathrm{x}+4.3131$ & 0.98 & $\mathrm{y}=-0.0868 \mathrm{x}+8.1638$ & 0.91 \\
\hline $\begin{array}{l}\text { Sayama- } \\
\text { Kaori }\end{array}$ & $\mathrm{y}=0.504 \mathrm{x}+0.3214$ & 0.97 & $\mathrm{y}=-0.0947 \mathrm{x}+8.5326$ & 0.94 \\
\hline Fushun & $\mathrm{y}=0.3975 \mathrm{x}+6.3236$ & 0.89 & $\mathrm{y}=-0.0896 \mathrm{x}+8.0562$ & 0.95 \\
\hline Meiryoku & $\mathrm{y}=0.4082 \mathrm{x}+4.4508$ & 0.89 & $\mathrm{y}=-0.0926 \mathrm{x}+8.5441$ & 0.97 \\
\hline Yabukita & $\mathrm{y}=0.4702 \mathrm{x}+2.5584$ & 0.96 & $\mathrm{y}=-0.1121 \mathrm{x}+9.1617$ & 0.99 \\
\hline
\end{tabular}

As a result of correlation analysis and simple regression analysis of NDF and total nitrogen with the number of growing days from the germination stage of Ichiban-Cha, the rate of increase of NDF was about 0.4 to $0.5 \%$ per day, and the contribution rate of the number of growing days $\left(\mathrm{r}^{2}\right)$ showed a strong correlation of 0.89 or higher for all varieties. In addition, the rate of increase in total nitrogen was about -0.09 to $-0.11 \%$ per day, and the contribution rate $\left(\mathrm{r}^{2}\right)$ of the number of growing days showed a strong correlation of 0.91 or more for all varieties.

\section{CONCLUSION}

Method for most appropriate plucking date determination based on the elapsed days after sprouting with Near Infrared: NIR reflection from Sentinel-2 data is proposed. Depending on the elapsed days after sprouting, tealeaf quality is decreasing. On the other hand, tealeaf yield is increasing with increasing of the days after sprouting. Therefore, there is most appropriate plucking date is very important.

Usually, it is determined by the normalized Difference Vegetation Index: NDVI derived from handheld NDVI cameras, drone mounted NDVI cameras, and visible to NIR radiometer onboard satellites because NIR reflection and NDVI depend on tealeaf quality and yield. It, however, does not work well in terms of poor regression performance and species dependency. Moreover, it takes time consumable works for finding appropriate tealeaves from the acquired camera images.

The proposed method uses only the days after sprouting. Next thing it has to do is to determination of sprouting date. In order to determine the date, optical sensor onboard Sentinel-2 data is used. Through experiment with the truth data taken at the intensive study area of the Oita Prefectural Agriculture, Forestry and Fisheries Research Guidance Center: OPAFFRGC, it is found that the proposed method is validated.

\section{FUtURE RESEARCH WORKS}

Further experimental studies are required for further validation of the proposed method for determination of the most appropriate plucking date for harvesting good quality of tealeaves of new flesh tealeaves (Ichiban-Cha).

\section{ACKNOWLEDGMENT}

The author would like to thank Professor Dr. Hiroshi Okumura and Professor Dr. Osamu Fukuda for their valuable discussions.

\section{REFERENCES}

[1] J.T.Compton, Red and photographic infrared linear combinations for monitoring vegetation, Journal of Remote Sensing of Environment, 8, 127-150, 1979.

[2] C.Wiegand, M.Shibayama, and Y.Yamagata, Spectral observation for estimating the growthth and yield of rice, Journal of Crop Science, 58, 4, 673-683, 1989.

[3] S.Tsuchida, I.Sato, and S.Okada, BRDF measurement system for spatially unstable land surface-The measurement using spectroradiometer and digital camera- Journal of Remote Sensing, 19, 4, 49-59, 1999.

[4] Kohei.Arai, Lecture Note on Remote Sensing, Morikita-shuppan Co., Ltd., 2000.

[5] Kohei.Arai and Y.Nishimura, Degree of polarization model for leaves and discrimination between pea and rice types of leaves for estimation of leaf area index, Abstract, COSPAR 2008, A3.10010-08\#991, 2008.

[6] Kohei.Arai and Long Lili, BRDF model for new tealeaves and new tealeaves monitoring through BRDF monitoring with web cameras, Abstract, COSPAR 2008, A3.10008-08\#992, 2008.

[7] Greivenkamp, John E., Field Guide to Geometrical Optics. SPIE Field Guides vol. FG01. SPIE. ISBN 0-8194-5294-7, 2004.

[8] Seto R H. Nakamura, F. Nanjo, Y. Hara, Bioscience, Biotechnology, and Biochemistry, Vol.61 issue9 1434-1439 1997.

[9] Sano M, Suzuki M ,Miyase T, Yoshino K, Maeda-Yamamoto, M.,J.Agric.Food Chem., 47 (5), 1906-1910 1999.

[10] Kohei Arai, Method for estimation of grow index of tealeaves based on Bi-Directional reflectance function: BRDF measurements with groundbased network cameras, International Journal of Applied Science, 2, 2, 52-62, 2011.

[11] Kohei Arai, Wireless sensor network for tea estate monitoring in complementally usage with Earth observation satellite imagery data based on Geographic Information System (GIS), International Journal of Ubiquitous Computing, 1, 2, 12-21, 2011.

[12] Kohei Arai, Method for estimation of total nitrogen and fiber contents in tealeaves with ground-based network cameras, International Journal of Applied Science, 2, 2, 21-30, 2011.

[13] Kohei Arai, Monte Carlo ray tracing simulation for bi-directional reflectance distribution function and grow index of tealeaves estimation, International Journal of Research and Reviews on Computer Science, 2, 6, 1313-1318, 2011.

[14] Kohei Arai, Fractal model-based tea tree and tealeaves model for estimation of well opened tealeaf ratio which is useful to determine tealeaf harvesting timing, International Journal of Research and Review on Computer Science, 3, 3, 1628-1632, 2012.

[15] Kohei Arai, Method for tealeaves quality estimation through measurements of degree of polarization, leaf area index, photosynthesis available radiance and normalized difference vegetation index for characterization of tealeaves, International Journal of Advanced Research in Artificial Intelligence, 2, 11, 17-24, 2013.

[16] Kohei Arai, Optimum band and band combination for retrieving total nitrogen, water, and fiber in tealeaves through remote sensing based on regressive analysis, International Journal of Advanced Research in Artificial Intelligence, 3, 3, 20-24, 2014.

[17] Kohei Arai, Yoshihiko Sasaki, Shihomi Kasuya, Hideto Matsuura, Appropriate tealeaf harvest timing determination based on NIR images of tealeaves, International Journal of Information Technology and Computer Science, 7, 7, 1-7, 2015.

[18] Kohei Arai, Yoshihiko Sasaki, Shihomi Kasuya, Hideo Matsura, Appropriate harvest timing determination referring fiber content in tealeaves derived from ground based NIR camera images, International Journal of Advanced Research on Artificial Intelligence, 4, 8, 26-33, 2015. 
[19] Kohei Arai, Method for Vigor Diagnosis of Tea Trees Based on Nitrogen Content in Tealeaves Relating to NDVI, International Journal of Advanced Research on Artificial Intelligence, 5, 10, 24-30, 2016.

[20] Kohei Arai, Cadastral and Tea Production Management System with Wireless Sensor Network, GIS, Based System and IoT Technology, International Journal of Advanced Computer Science and Applications, 9, 1, 38-42, 2018.

[21] Kohei Arai, Lili, Long --BRDF model for new tealeaves and tealeaves monitoring with network cameras, Saga University Faculty of Science and Engineering Bulletin, 38, 1, 23-28, 2009.

[22] Kohei Arai and Long Lili, BRDF model for new tealeaves on old tealeaves and new tealeaves monitoring through B RDF measurement with web cameras, Abstract of the 50th COSPAR(Committee on Space Research/ICSU) Congress, A3.1-0008-08 ,992, Montreal, Canada, July, 2008.

[23] Kohei Arai, Estimation method for total nitrogen and fiber contents in tealeaves as well as grow index of tealeaves and tea estate monitoring with network cameras, Proceedings of the IEEE Computer Society, Information Technology in Next Generation, ITNG, 595-600, 2009.

[24] Kohei Arai, Multi-Layer Observation for Agricultural (Tea and Rice) Field Monitoring, Proceedings of the Seminar at Bogor Agriculture University, Keynote Speech, 2016.

\section{Authors' PROFILE}

Kohei Arai, He received BS, MS and PhD degrees in 1972, 1974 and 1982, respectively. He was with The Institute for Industrial Science and Technology of the University of Tokyo from April 1974 to December 1978 also was with National Space Development Agency of Japan from January, 1979 to March, 1990. During from 1985 to 1987, he was with Canada Centre for Remote Sensing as a Post Doctoral Fellow of National Science and Engineering Research Council of Canada. He moved to Saga University as a Professor in Department of Information Science on April 1990. He was a councilor for the Aeronautics and Space related to the Technology Committee of the Ministry of Science and Technology during from 1998 to 2000 . He was a councilor of Saga University for 2002 and 2003. He also was an executive councilor for the Remote Sensing Society of Japan for 2003 to 2005. He is a Science Council of Japan Special Member since 2012. He is an Adjunct Professor of University of Arizona, USA since 1998. He also is Vice Chairman of the Science Commission "A" of ICSU/COSPAR since 2008 then he is now award committee member of ICSU/COSPAR. He wrote 55 books and published 620 journal papers as well as 450 conference papers. He received 66 of awards including ICSU/COSPAR Vikram Sarabhai Medal in 2016, and Science award of Ministry of Mister of Education of Japan in 2015. $\mathrm{He}$ is now Editor-in-Chief of IJACSA and IJISA. http://teagis.ip.is.sagau.ac.jp/index.html. 